\title{
Optimization of an autonomous hybrid renewable energy system using reformed electric system cascade analysis
}

\author{
Ranjay Singh and Ramesh C. Bansal, Senior Member, IEEE
}

\begin{abstract}
This paper presents reformed electric system cascade analysis (RESCA) technique for optimization of hybrid renewable energy system (HRES) comprising of wind energy conversion system (WECS), photo-voltaic system (PV), battery energy storage system (BESS) and non-intermittent source (NIS). Optimization constraints of final excess energy (FEE), energy generation ratio (EGR), cost of energy (COE), net present cost (NPC) and renewable energy fraction (REF) are considered for the optimization of the system. This optimization is realized for an isolated load comprising of the $\mathbf{1 0}$ households in Malaysia with a daily consumption of $84.5 \mathrm{kWh}$. On successful implementation of RESCA with different constraints it is found that the optimum size of energy sources for the HRES varies depending on the chosen constraints. Also, the net present cost (NPC) of the system can be considerably reduced on introduction of NIS to the HRES. RESCA provides the user with better insight into the influence of variation of PV and WECS power generation while identifying the optimal size of energy storage unit. The optimized results obtained are also compared with benchmark HOMER software to validate the methodology.
\end{abstract}

Index Terms-Batteries, design optimization, hybrid power system, iterative algorithm, solar energy, wind energy.

\section{INTRODUCTION}

Due to the ever-increasing demand of energy in the world along with greater awareness towards the harmful impacts of the convention fossil fuels, has brought acute attention to renewable energy generation in past two decades. Among renewable sources the most popular resources are wind and PV [1]. PV system has ease of installation and lower maintenance cost, PV installation capacity of the world at the end of 2017 is $397 \mathrm{GW}$ which is projected to increase to 489 GW by 2020 and 1760 GW by 2030 [2]. Wind energy is also a fast growing green energy source with worldwide installation capacity of $540 \mathrm{GW}$ at the end of 2017 which is expected to increase to $800 \mathrm{GW}$ by 2020 and $2000 \mathrm{GW}$ by 2030 [2]. Penetration of renewable energy into to the current grid reduces the energy demand from the conventional energy sources, but recently stand-alone hybrid systems with high renewable energy penetration has gained popularity for complete pollution free energy generation, especially for isolated loads which are not connected to the grid [3]-[6]. Due to uncertainty in renewable sources like solar and wind it is prudent to add storage unit to the isolated system. Addition of storage unit increases the cost and control complexity of the system but provides higher reliability of power supply [7], [8]. Multiple energy sources and storage unit control complexity creates the problem of optimal sizing of the system components. There are many techniques adopted by researchers for optimization of Hybrid Energy System (HES), e.g., Upadhyay et al. [9] have found the most economic configuration of HES with diesel generator using Particle Swarm Optimization (PSO). Maleki et al. [10] have found PSO to be the most effective technique among other Artificial Intelligence (AI) techniques for optimization of HES with battery and fuel cell as storage systems. Katsigiannis et al. [11] have used Simulated Annealing (SA) and Tabu Search (TS) techniques to find optimum scheduling of small autonomous power system to reduce the cost of energy. Paliwal et al. [12] have carried out the reliability analysis of isolated HRES in a rural area using PSO. Koutroulis et al. [13] used Genetic Algorithm (GA) for optimization of a HES comprising of PV, WECS and diesel generator feeding a desalination system. Bahramara et al. [14] have presented literature review of various studies for optimal planning of isolated HRES using HOMER. Hove et al. [15] using RETScreen presented economic analysis of a HES consisting of PV and diesel generators based on renewable energy fraction. Singh et al. [16] have compared grid connected and isolated mode of operation of a HRES feeding a residential load in Mumbai based on COE using HOMER. The software tools which can be used for the optimization process as presented in [17] and the application AI techniques for optimization of HES are presented in [10]. The major drawbacks of software tools like HOMER, RETScreen, HYBRID2, etc. are, that the user has to input the size of the various components and the software provides results based on only the input range, whereas, the optimum solution can lie outside the input range of the user. HOMER considers only a single objective function to minimize the NPC and it does not consider intra hour variability [17]. HYBRID2 has limited access to the system parameters [17]. iHOGA can simulate loads limited to average daily consumption of $10 \mathrm{kWh}$ and sensitivity and probability analysis is not included [17]. These software basically provide the most feasible solution based on economics and does not guide the user to a predefined type of solution based on performance parameters. The underlying optimization process is hidden from the user, who gets no idea or feedback to why the solution obtained is the best. For Artificial Intelligence (AI) techniques, prior knowledge of the working of these techniques is required. It is somewhat difficult to correlate and find analogues parameters and functions for these techniques to optimize HRES. For GA approach, finding the best solution is not guaranteed, as it depends on the maximum generation set and the optimal solution may not be analyzed. For neural network techniques, the solution depends on the training process and after the system is trained introducing flexibilities in evaluation is 
problematic [18]. For fuzzy logic approach, estimation of membership function is a difficult and time consuming process [18]. The major drawbacks of AI techniques are that for complex system with several system components the solution complexity, convergence time and computation power required increase [18].

Therefore, a novel RESCA technique is introduced in this paper. It is a systematic and simple technique for the optimization of HRES which provides better insight into the sizing of energy sources and storage unit with its cascade table and its graphical representations.

RESCA is a technique which is primarily based on pinch analysis, used during optimization of raw material like heat, mass, carbon and gasses [19]. Wan et al. [20] implemented this method to minimize the outsourced electricity for a grid connected load. Bandyopadhyay [21] implemented power pinch analysis (PoPA) for the design and optimization of battery storage unit of an isolated energy system. Ho et al. [22] further improved upon this technique and introduced a new iterative method of ESCA which could optimize both the non-intermittent source of biomass and energy storage unit for distributed generation system. Ho et al. [23] further extended the research to optimize an isolated system with intermittent source of PV and BESS. All these works provide a deep insight into the successful implementation of PoPA and ESCA in optimization of the renewable energy system. RESCA is therefore developed as an extension to the work of Ho et al. [22] and is capable of handling multiple energy sources like PV, WECS and NIS. Also incorporated into RESCA is its ability of handling multi-constraint optimization of the HRES system.

The subsequent paper is organized as follows: Section II. describes the isolated HRES configuration with mathematical models of system components. Section III, briefly describes various optimization constraints and mathematical expression. Section IV, introduces the RESCA methodology and elucidates various optimization algorithm. Section V. presents the results obtained on implementation of the RESCA technique for the case study and also compares them with that obtained from HOMER. Finally, Section VI. provides important conclusion from the results.

\section{ISOLATED HYBRID SYSTEM CONFIGURATION}

The irregular power generation from a single renewable energy source can be reduced by combining more than one energy sources. The most commonly used combined energy sources are PV and wind systems as they use two different energy source for power generation, using them together can achieve synergy in the following ways [24]:

i. Stabilize output power generation.

ii. Seasonal variations are equalized.

iii. Reduction in size of energy storage system.

iv. Reduction in size of NIS if used.

The architecture of the renewable energy sources can be broadly classified into three categories AC bus, DC bus and hybrid architecture consisting of both $\mathrm{AC}$ and DC buses. The choice of AC or DC bus architecture can be made based on the comparison presented in Table I [25], [26]. The hybrid architecture which is adopted in this paper is also implemented by benchmark software like HOMER, HYBRID2, TRNSYS, etc. It incorporates the advantages of both AC bus and DC bus architecture by reducing the conversion stages thereby reducing the cost and increasing the reliability of the system.
The architecture of the HRES is shown in Fig. 1 [27], [28]. It consists of a PV system and BESS connected to a DC bus. The WECS, primary load, dummy load and NIS are connected to the AC bus. It is assumed that output voltages of system components are in synchronization with the buses they are connected to. The AC and DC bus are linked by a converter. The energy losses during power conversion and charging/discharging of the battery are taken into consideration during the analysis. The motive for adding NIS on the AC bus is to further reduce the system cost which is presented in later section of this paper. The advantage of adding a dummy load is that it can absorb the excess energy which can no longer be stored in the BESS. This dummy load can be water heating system, space cooling system, etc. Brief modelling of the main subsystems is shown in Fig. 1.

Table I Comparison of AC bus and DC bus HRES architecture

\begin{tabular}{|c|c|c|}
\hline Parameter & AC bus & DC bus \\
\hline Topology & $\begin{array}{l}\text { Complex with larger } \\
\text { converter stages }\end{array}$ & Relatively simple \\
\hline $\begin{array}{l}\text { Controller } \\
\text { complexity }\end{array}$ & $\begin{array}{l}\text { Difficult as } \mathrm{AC} \\
\text { system transients are } \\
\text { more complex }\end{array}$ & $\begin{array}{l}\text { Easier as topology is } \\
\text { relatively simpler }\end{array}$ \\
\hline Power quality issues & $\begin{array}{l}\text { Relatively complex as } \\
\text { voltage, frequency } \\
\text { power factor and } \\
\text { phase angle have to } \\
\text { be controlled }\end{array}$ & $\begin{array}{l}\text { Only voltage issue is } \\
\text { to be catered therefore } \\
\text { higher power quality } \\
\text { can be provided to the } \\
\text { consumer }\end{array}$ \\
\hline Efficiency & $\begin{array}{l}\text { Less efficient (more } \\
\text { conversion stages) }\end{array}$ & $\begin{array}{l}\text { More efficient (less } \\
\text { conversion stages) }\end{array}$ \\
\hline Standardization & $\begin{array}{l}\text { Better AC standards } \\
\text { existing }\end{array}$ & $\begin{array}{ll}\begin{array}{l}\text { Still under } \\
\text { construction }\end{array} & \\
\end{array}$ \\
\hline Protection & 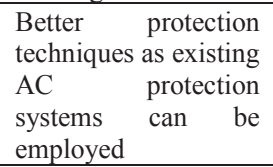 & $\begin{array}{l}\text { DC protection is } \\
\text { difficult and still } \\
\text { under research }\end{array}$ \\
\hline Stability & $\begin{array}{l}\text { Less stable as voltage } \\
\text { and frequency } \\
\text { synchronization is } \\
\text { required for all the } \\
\text { components }\end{array}$ & $\begin{array}{l}\text { More robust as only } \\
\text { voltage needs to be } \\
\text { controlled }\end{array}$ \\
\hline Reliability & $\begin{array}{l}\text { Lower than DC, as } \\
\text { more devices are used } \\
\text { leading to higher } \\
\text { probability of failure }\end{array}$ & Higher \\
\hline Cost & $\begin{array}{l}\text { Relatively lower cost } \\
\text { if existing system } \\
\text { devices are used. }\end{array}$ & $\begin{array}{l}\text { Relatively less costly } \\
\text { if a completely new } \\
\text { system architecture is } \\
\text { designed }\end{array}$ \\
\hline
\end{tabular}

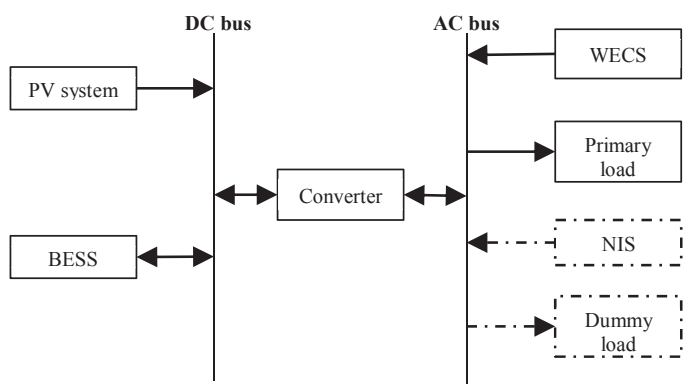

Fig. 1 Block diagram of hybrid energy system

\section{A. PV model}

The PV module performance is dependent on various factors like solar radiation, temperature and other weather variables. The hourly energy output from a PV module of area $A_{P V}$ can be calculated by (1) [29]:

$$
G_{t}^{P V}=N_{P V} * R_{t} * A_{P V} * \eta_{P V}
$$

Where, $G_{t}^{P V}$ is the hourly energy generation in Wh from the $\mathrm{PV}$ generation system, $N_{P V}$ is the number of $\mathrm{PV}$ units, $R_{t}$ is the 
hourly solar radiation in $\mathrm{Wh} / \mathrm{m}^{2}$ and $\eta_{P V}$ is the efficiency of the PV conversion system.

\section{B. Wind energy conversion system model}

The power output from a wind turbine is strongly dependent on wind speed. The cut-in speed $v_{c}$ is the wind speed above which the wind turbine generates electricity. The power output increases in accordance to Weibull shape parameter till the rated speed $v_{r}$ is achieved. Between rated speed and cutout speed $v_{f}$, the power output remains constant at the rated power, $P_{r}$. Beyond $v_{f}$, power generation reduces to zero to maintain the mechanical integrity of the WECS [30]. Therefore the hourly wind turbine generation can be written as (2) [31], [32]:

$$
G_{t}^{W}= \begin{cases}P_{r} \frac{v^{k}-v_{c}^{k}}{v_{r}^{k}-v_{c}^{k}}, & v_{c}<v<v_{r} \\ P_{r} & , v_{r}<v<v_{f} \\ 0 & , \text { otherwise }\end{cases}
$$

Where, $G_{t}^{W}$ is the hourly energy generation of the WECS in $\mathrm{Wh}, k$ is the Weibull shape parameter which is assumed to be one, thereby making the increase in power from $v_{c}$ to $v_{r}$ linear [33].

The total hourly energy generation of the HRES at the AC bus can be calculated by (3):

$$
G_{t}=\left(\eta_{\text {conv. }} \times G_{t}^{P V}\right)+G_{t}^{W}
$$

Where, $G_{t}$ is the net hourly energy generation at AC bus in $\mathrm{Wh}$ and $\eta_{\text {conv }}$ is the converter efficiency. The WECS is connected directly to the AC bus where the load voltage and WECS output voltage is in synchronization with AC bus voltage, therefore no conversion loss is encountered by the WECS in furnishing primary load.

\section{Battery energy storage system model}

BESS is an essential part of the HRES as it increases the reliability of the system by providing power to the load, when energy sources are unable to cater the primary load. During excess energy generation from the PV and WECS the BESS is charged and during deficiency of energy generation BESS is discharged to carter to the primary load. The net hourly surplus energy is given by (4) which is used to simulate the BESS.

$$
N_{t}=G_{t}-L_{t}
$$

Where, $L_{t}$ is the hourly load demand in $\mathrm{Wh}$, and $N_{t}$ the net hourly surplus generation in Wh.

The batteries are charged when $N_{t}$ is positive as shown in (5) [34]:

$$
C_{t}= \begin{cases}N_{t} * \eta_{\text {char }} * \eta_{\text {conv. }}, & N_{t}>0 \\ 0 & , N_{t} \leq 0\end{cases}
$$

Where, $C_{t}$ is the hourly energy by which BESS is charged in Wh, $\eta_{\text {char }}$ is the charging efficiency.

The batteries are discharged when $N_{t}$ is negative as shown in (6) [34]:

$$
D_{t}= \begin{cases}N_{t} /\left(\eta_{\text {disch }} * \eta_{\text {conv. })}\right) & N_{t}<0 \\ 0 & , N_{t} \geq 0\end{cases}
$$

Where, $D_{t}$ is the hourly energy by which BESS is discharged in Wh, $\eta_{\text {disch }}$ is the discharging efficiency. In both charging and discharging of the BESS the conversion losses have been considered.

The net cumulative energy of the BESS after the load has been catered, can be calculated by (7).

$$
C E_{t}=C E_{t-1}+C_{t}+D_{t}
$$

Where, $C E_{t}$ is the cumulative energy in the current time interval in $\mathrm{Wh}$ and $C E_{t-1}$ is the cumulative energy in the previous time interval in $\mathrm{Wh}$.

The number of batteries required for the BESS can be calculated as shown in (8) [34]:

$$
N_{\text {bat }}=\frac{N C E_{t}(\max )}{I_{b a t} * V_{b a t} * D O D}
$$

Where, $N_{b a t}$ is the number of batteries in the BESS, $N C E_{t}$ is the net cumulative energy after pinch point adjustment in Wh, DOD is the depth of discharge of battery, $V_{b a t}$ is the output voltage of the battery and $I_{b a t}$ is the charge capacity of the battery in Ah. The BESS energy management strategy is shown in Fig. 2, where SOC is state of charge of battery.

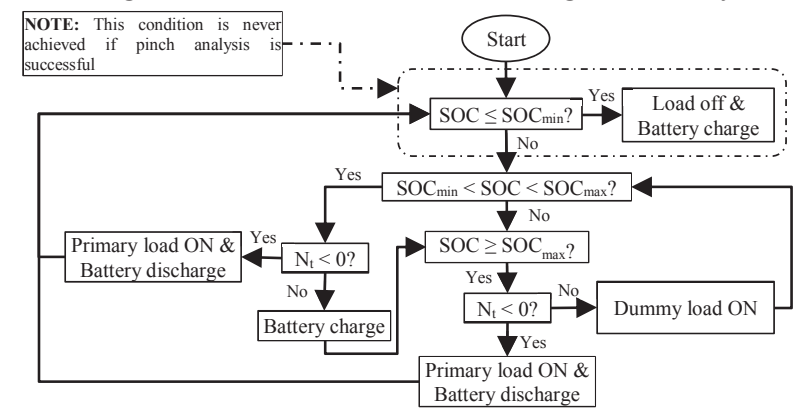

Fig. 2 Battery energy management strategy

\section{Converters}

The converter is an essential part of the system architecture as it helps in the flow of power between the AC and DC components. The converter capacity is given by (9) [23]:

$$
P_{\text {conv }}=\frac{\max \left(G^{P V} L_{t}, G^{W}\right)}{\eta_{\text {conv. }}}
$$

Where, $P_{\text {conv }}$ is the rating of the converter in Watts.

The converter has three primary conversion, firstly the energy conversion of DC power from $\mathrm{PV}$ to $\mathrm{AC}$ bus, secondly conversion of AC power from WECS to DC bus to charge the BESS after load is furnished and thirdly, from DC to AC conversion of the energy when BESS is catering to the load. Therefore, the maximum load encountered during these conversion is used to find the converter rating.

\section{OPTIMIZATION CONSTRAINTS}

There are various constraints like cost of energy, annual system cost, net present cost, energy generation ratio, etc. on which the HRES can be optimized. The RESCA technique is implemented with few of these constraints as explained below.

\section{A. Final excess energy (FEE)}

$F E E$ is a primary constraint which helps to find the most optimum size of the BESS for the HRES based on reliability of the system, hence for multi-constraint optimization evaluation of FEE is mandatory for isolated HRESs. FEE is net charge accumulated in the BESS at the end of time period of analysis and is expressed as the difference between the charge in BESS at the end and beginning of the analysis, which can be calculated by (10):

$$
F E E=C E_{t=T}-C E_{t=0}
$$

Where, $\mathrm{T}$ is the time period of the analysis. Reducing the FEE helps in optimizing the size of the BESS and thereby reducing the cost.

FEE also helps in estimating the reliability of the system by evaluation of Loss of Load ( $L O L)$, Loss of Power Supply 
Probability (LPSP) [35] and System Average Interruption Duration Index (SAIDI), defined under IEEE Standard 13662003 as ratio of duration of interruption and duration of operation [36]. They can be evaluated using (11-14).

$$
\begin{gathered}
L O L= \begin{cases}0, & F E E \geq 0 \\
F E E, & F E E<0\end{cases} \\
L P S P= \begin{cases}0, & F E E \geq 0 \\
\frac{F E E}{\sum L_{t} * T}, F E E<0\end{cases} \\
S A I D I=\frac{t_{\text {intrupt }}}{T} \\
\text { where, } t_{\text {intrupt }}=\sum_{t=1}^{T} t \quad \forall C E(t)<0
\end{gathered}
$$

A positive FEE over-estimates the storage unit size which leads to excess charge accumulation in BESS with a reliability of unity. Whereas, a negative FEE under-estimates the BESS which leads to depletion of charge in the BESS during cyclic system operation leading to loss of supply and reliability $<1$. During optimization ideally FEE $=0$, but it is preferred to keep FEE slightly greater than zero, as it makes the system capable of handling slight variation in load demand. Also, the excess charge, if generated can be provided to dummy load making the system balanced at all times. This flexibility is not conceivable in case FEE is chosen slightly less than zero. For the scope of this paper all considered systems are optimized with zero loss of power.

\section{B. Cost of energy (COE)}

$C O E$ is an important constraint as it helps to estimate the cost of each energy unit generated by HRES. The main aim of choosing this constraint is to find the most optimum combination of number of PV and WECS which has the minimum cost of energy generation. $C O E$ of the system is calculated in (15) [35]:

$$
C O E=\frac{\left(C R F * C_{T S C}\right)}{365 * \sum_{t=1}^{24} L_{t}}+L C E_{N I S}
$$

Where, $\quad C_{T S C}=N_{a} *\left(\sum_{a \in P V, W, b a t}\left(C_{C, a}+\right.\right.$

$\left.\left.C_{M \& O, a}+C_{I, a}\right)\right)+C_{B O S}$

and, $\quad C R F=\frac{r *(1+r)^{i}}{(1+r)^{i}-1}$

Where, $C R F$ is the capital recovery factor determined by (13), $r$ is the annual rate of interest, $i$ is the lifetime of the system which is assumed to be $25 \mathrm{yrs}$., $C_{T S C}$ is the total system cost, $L C E$ is levelized cost of energy of NIS system used, $C_{C}$ is the capital cost of components, $C_{M \& O}$ is the maintenance and operation cost of the components and $C_{I}$ is the installation cost of the system, $C_{B O S}$ is balance of system cost. As can be seen from (15-17) the total system cost is inclusive of all expenses, to get the most accurate $C O E$ value.

\section{Energy generation ratio (EGR)}

$E G R$ is calculated for system with more than one energy generation source and a balance of power generation between the energy sources has to be maintained. The EGR for a system consisting of PV and WECS as energy sources is given by (18):

$$
\begin{aligned}
E G R & =G F_{W} / G F_{P V} \\
\text { where, } G F_{W} & =\frac{\sum_{t=1}^{T} G_{t}^{W}}{\sum_{t=1}^{T} G_{t}^{W}+\sum_{t=1}^{T} G_{t}^{P V}}
\end{aligned}
$$

$$
\text { and } G F_{P V}=\frac{\sum_{t=1}^{T} G_{t}^{P V}}{\sum_{t=1}^{T} G_{t}^{W}+\sum_{t=1}^{T} G_{t}^{P V}}
$$

Where, $G F_{W}$ and $G F_{P V}$ is the generation fraction of WECS and $\mathrm{PV}$ respectively. $E G R>1$ signify that the energy generated by WECS is more than energy generated by PV, $E G R<1$ signify that the energy generated by $\mathrm{PV}$ is more and $E G R$ of one signifies that the energy generated by WECS and $\mathrm{PV}$ are equal in the time period of analysis.

\section{Renewable energy fraction (REF)}

Unlike wind and PV, energy generation from NIS is continuous and is independent of the weather condition. NIS may be added to the hybrid system thereby reducing the size of PV, WECS and BESS required and also increasing the reliability of the system [37]. The drawback of NIS is that the maintenance and operation cost of such systems is higher in comparison to wind and PV, as a constant supply of fuel is required. The $R E F$ is calculated in (21) as mentioned [38], [39]:

$$
R E F=1-\frac{\sum_{t=1}^{T} G_{t}^{N I S}}{\sum_{t=1}^{T} L_{t}}
$$

Where, $G_{t}^{N I S}$ is the hourly energy generated by NIS in Wh. It is assumed that the NIS produces a constant power equal to its rating during the time interval of analysis. Due to the harmful impact of fossil fuel based NIS like diesel generators, renewable NIS like bio-mass generator, micro-hydro or even geothermal generation may be considered depending on the fuel availability and location of the site. For the scope of this paper bio-mass generator is chosen as the NIS. Due to the higher cost of the NIS the REF should be prudently chosen by the system planner.

\section{REFORMED ELECTRIC SYSTEM CASCADE ANALYSIS}

Due to various components of the HRES, optimization of the size of each component is necessary for economic and reliability reasons. Thus, the RESCA technique incorporates different optimization constraints like FEE, COE, NPC, EGR, and $R E F$ for the optimization process. The conjectural basis of RESCA is power pinch analysis, a novel technique which is used to determine the size of the storage unit after the optimization of the energy source. All the algorithms of RESCA implementation require a common approach of extracting data and creation of a cascade table. The list of data required for the construction of cascade table are as follows: time period of analysis, hourly load demand, hourly solar radiation profile, hourly wind speed profile, PV module efficiency and rated power, wind turbine cut-in, cut-out, and rated speed, wind turbine rated power, converter efficiency and characteristics of battery. Hybrid cascade table (HCT) is unified in RESCA for optimization of the energy sources and to find the pinch point of the analysis (obtained after optimization constraints are met). When the data extraction is complete the HCT is generated, as presented in Section V.A, where each row represents one-time step and each column represents a system property which are calculated using (110). The novelty and flexibility of RESCA lies in its ability of handling the multi-source optimization irrespective of the initial assumption of energy sources. As shown in algorithms presented in Section IV. (A-C), the common approach is to create a HCT, but updating of energy units size vary depending on the constraints implemented. 


\section{A. Algorithm for FEE constraint}

FEE is the base constraint for optimization, it is implemented as shown in Fig. 3. The tolerance of FEE is set at $100 \mathrm{Wh}$, if the condition is not met then the energy source size is optimized based on three scenarios.

Scenario 1: If FEE is greater than the net energy generated by one wind turbine $\left(P_{w I}\right)$ and net energy generated by one PV $\left(P v_{l}\right)$, then, increase or decrease both $N_{P V}$ and $N_{W}$, if FEE is negative or positive respectively.

Scenario 2: If FEE is less than the $P_{w l}+P v_{l}$ and greater than $P w_{l}$, then increase or decrease $N_{W}$, if $F E E$ is negative or positive respectively.

Scenario 3: If FEE is less than the $P_{w l}$, then increase or decrease $N_{P V}$, if $F E E$ is negative or positive respectively.

These scenario incorporates the inclusion of weather flexibility into optimization. If weather at the site is windier it will lead to higher value of $P_{w l}$ leading to an optimized result which has higher wind generation contribution, if the site location is sunnier, leading to higher $P_{v l}$ the optimized result tilts towards PV generation.

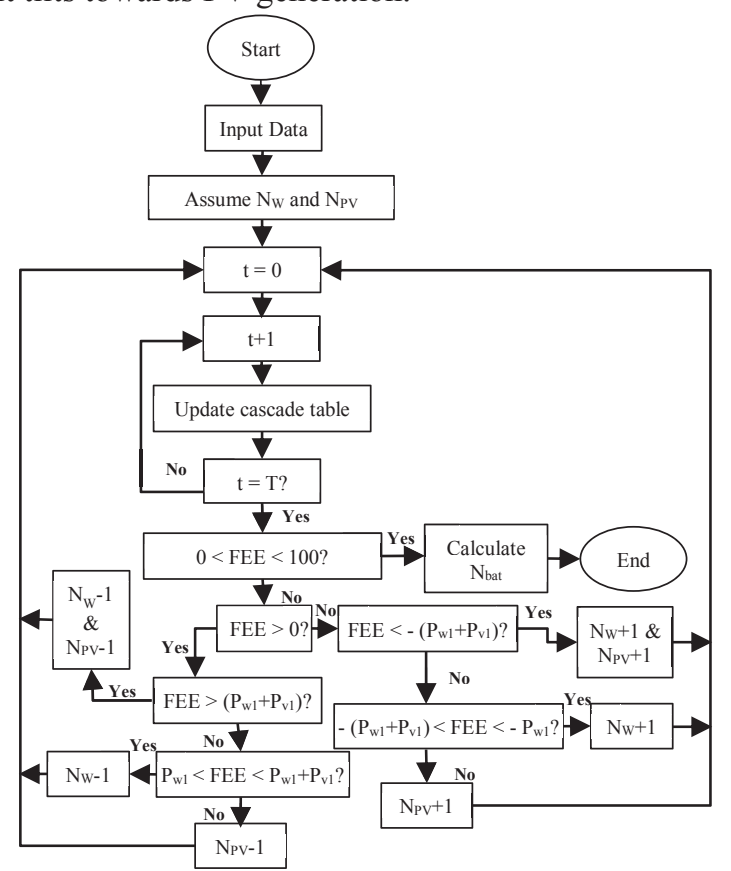

Fig. 3 Algorithm for RESCA implementation with FEE constraint only

\section{B. Algorithm for EGR and FEE constraints}

In this multi-criteria optimization, the system is optimized as shown in Fig. 4. The aim of this optimization is to maintain a balance between the energy generated between WECS and $\mathrm{PV}$. The tolerance level of FEE is fixed at $100 \mathrm{~W}$ and the aim is to optimize the system for an $E G R$ of 1 with $10 \%$ tolerance. The approach of optimization is as follows:

Scenario 1: For $E G R>1.10$, if FEE is negative then $N_{P V}$ is increased and if $F E E$ is positive $N_{W}$ is reduced.

Scenario 2: For $E G R<0.90$, if $F E E$ is negative the $N_{W}$ is increased and if $F E E$ is positive $N_{P V}$ is reduced.

Scenario 3: For $0.90<E G R<1.10$, if $F E E$ is positive $N_{P V}$ and $N_{W}$ are reduced and if FEE is negative $N_{P V}$ and $N_{W}$ are increased.

\section{Algorithm for COE and FEE constraints}

In this multi-criteria optimization, the aim is to reduce the $C O E$ and is implemented as shown in Fig. 5. The approach for optimization is to fix the size of WECS and find the optimized size of PV source based on the FEE constraint
WECS size is then incremented and new optimized size of PV is obtained. All the system configurations are tabulated until the optimized size of the PV obtained is less than 1. Once the tabulation is finished the $C O E$ for each combination is found, to obtain the best configuration of PV and WECS. It is to be noted that the reason of fixing WECS and not PV is the larger power capacity of each WECS in comparison to PV, which smoothen the approach to criteria realization. Once the tabulation of all optimized configuration is achieved, instead of $C O E$ any of the economic constraints like TSC, NPC, ASC, etc. can also be evaluated.

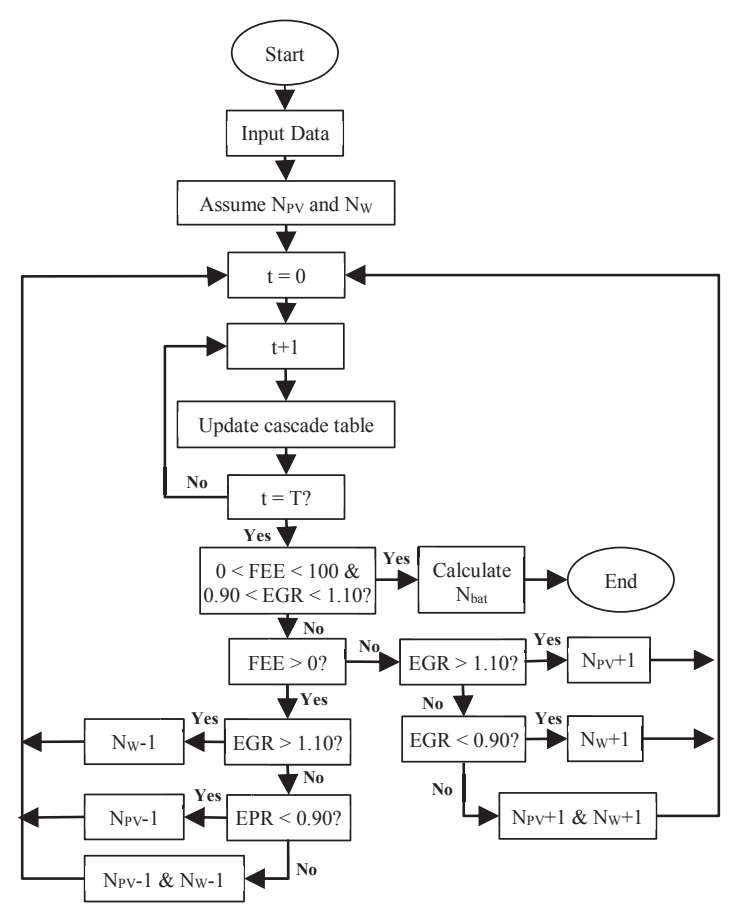

Fig. 4 Algorithm for RESCA implementation with EGR and FEE constraints

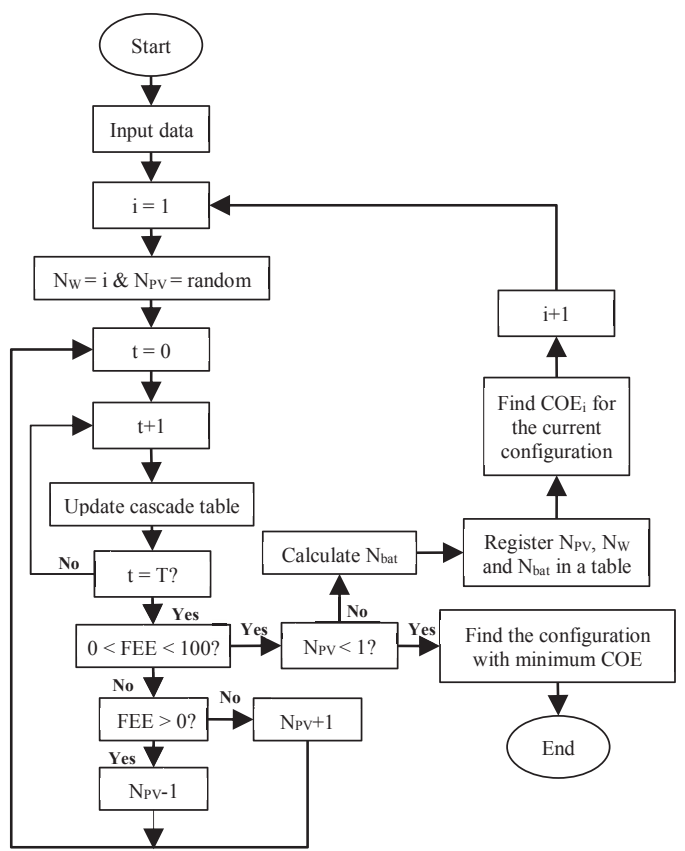

Fig. 5 Algorithm for RESCA implementation with COE and FEE constraints

\section{RESULTS AND DISCUSSION}

The developed RESCA methodology can be applied to any isolated HRES with PV, WECS, BESS and NIS irrespective 
of the site location. For the scope of this paper RESCA is applied for optimization of HRES catering to 10 average households in Malaysia with load, solar radiation and wind speed profile as shown in Fig. 6 [22], [40]. MATLAB software environment is used to implement and programme the solution based on the proposed RESCA. The tolerance for FEE constraint is fixed at $+100 \mathrm{Wh}$ and $E G R$ at $10 \%$. The data required for the construction of the HCT is shown in Table II [29], [41], [42].

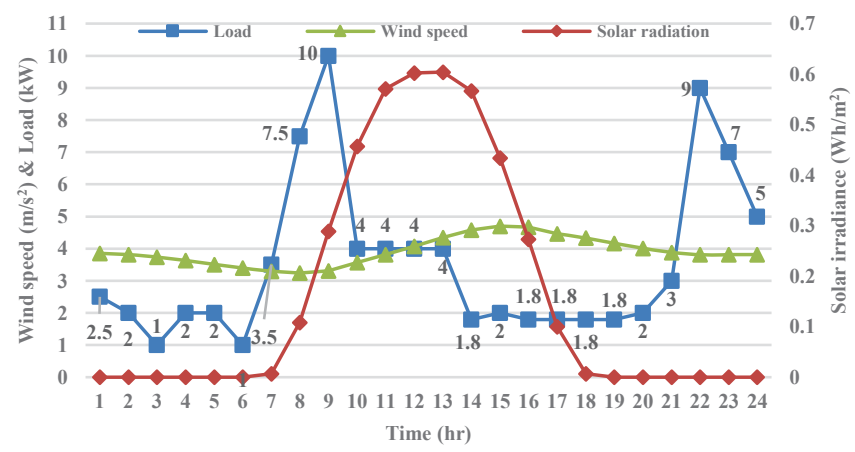

Fig. 6 Load, solar radiation and wind speed variation for the time period of analysis

Table II Data required for system modelling

\begin{tabular}{|l|l|}
\hline \multicolumn{2}{|c|}{ General data } \\
\hline Period of analysis data & $24 \mathrm{hr}$ \\
\hline Time step & $1 \mathrm{hr}$ \\
\hline \multicolumn{2}{|c|}{} \\
\hline Type & Mono-crystalline \\
\hline Efficiency & $15 \%$ \\
\hline Area per unit & $1.9 \mathrm{~m}^{2}$ \\
\hline Cost per unit & $\$ 135$ \\
\hline M\&O cost per unit p.a. & $\$ 15$ \\
\hline Installation cost per unit & $\$ 20$ \\
\hline Balance of system & $\$ 600$ \\
\hline Life span & $25 \mathrm{yrs}$. \\
\hline \multicolumn{1}{|c|}{ Wind energy conversion system data } \\
\hline Type & $3 \mathrm{blades}$, PMSG \\
\hline Rated power & $1000 \mathrm{~W}$ \\
\hline Cut-in speed & $2.5 \mathrm{~m} / \mathrm{s}$ \\
\hline Rated speed & $10 \mathrm{~m} / \mathrm{s}$ \\
\hline Cut-out speed & $25 \mathrm{~m} / \mathrm{s}$ \\
\hline Cost per unit & $\$ 1700$ \\
\hline M\&O cost per unit p.a. & $\$ 100$ \\
\hline Installation cost per unit & $\$ 65$ \\
\hline Balance of system & $\$ 2000$ \\
\hline Life span & $25 \mathrm{yrs}$. \\
\hline \multicolumn{2}{|c|}{ Battery storage data } \\
\hline Type & Li-ion \\
\hline Battery capacity per unit & $220 \mathrm{Ah}$ \\
\hline Battery voltage & $24 \mathrm{~V}$ \\
\hline Charging efficiency & $88.3 \%$ \\
\hline Discharging efficiency & $88.3 \%$ \\
\hline Depth of discharge & $90 \%$ \\
\hline SOC max & $95 \%$ \\
\hline Cost per unit & $\$ 700$ \\
\hline Replacement cost & $\$ 600$ \\
\hline Life span & $5 \mathrm{yrs}$. \\
\hline \multicolumn{2}{|c|}{ Efficiency (dc/ac \& ac/dc) } \\
\hline
\end{tabular}

\begin{tabular}{|l|l|}
\hline Rating per unit & $500 \mathrm{~W}$ \\
\hline Cost per unit & $\$ 150$ \\
\hline Life span & $25 \mathrm{yrs}$. \\
\hline NIS levelized cost (bio-mass gen.) & $\mathbf{0 . 1 5} \mathbf{\$} / \mathbf{k W h}$ \\
\hline
\end{tabular}

\section{A. Implementation of RESCA with FEE constraint only}

Implementation of RESCA methodology as shown in Fig. 3 is done with an initial estimate of $N_{P V}=10, N_{W}=5$ and zero initial charge in BESS. After 19 iterations, the optimized values of $N_{P V}=27$ and $N_{W}=18$ are obtained with $F E E=+86$ Wh. The HCT table obtained for the optimized size of PV and WECS is shown in Table III. The energy generated by WECS and PV sources and the net energy surplus is shown in Fig. 7. The variations in magnitude of FEE and total power generated by PV and WECS with each iteration is presented in Fig. 8. For the initial estimate of $N_{P V}=10$ and $N_{W}=5, F E E$ is $-84.63 \mathrm{kWh}$ which progressively decreases after each iteration as the size of PV and WECS is optimized. As can be seen from Table III, the $C E$ reaches a minimum value of $13274 \mathrm{Wh}$ at $\mathrm{t}=$ 09:00 hrs, this point acts as the pinch point of the analysis. The energy deficiency at pinch point is the minimum charge required in BESS at the start of the analysis, on addition of this minimum charge a new cumulative energy $\left(N C E_{t}\right)$ column is created. Since all the values of $N C E$ are positive therefore no loss of load occurs making the $L O L=$ $L P S P=S A I D I=0$ and the pinch analysis is successful. The maximum value of $N C E(29212 \mathrm{Wh}$ at $\mathrm{t}=20: 00 \mathrm{hrs}$. $)$ is put in (8) to obtain $N_{b a t}=6$ (32.12 $\mathrm{kWh}$ capacity). The plots of the $C E_{t}, N C E_{t}$ and $N C E_{t}$ with depth of discharge $(D O D)$ adjustment are shown in Fig. 9

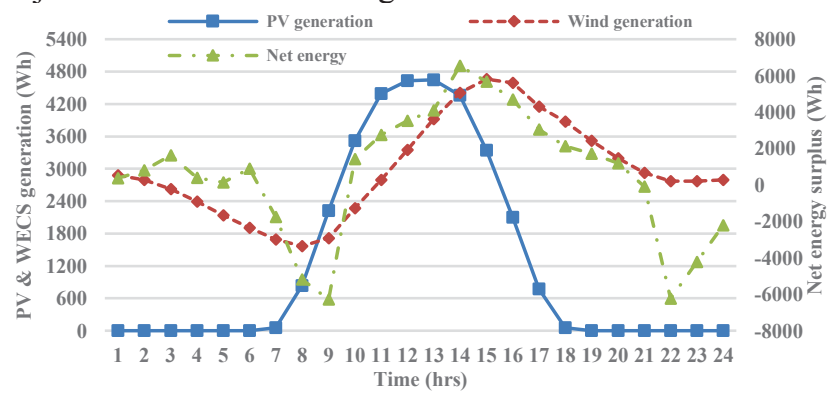

Fig. 7 Net energy required and energy generated by WECS and PV on RESCA implementation with FEE constraint

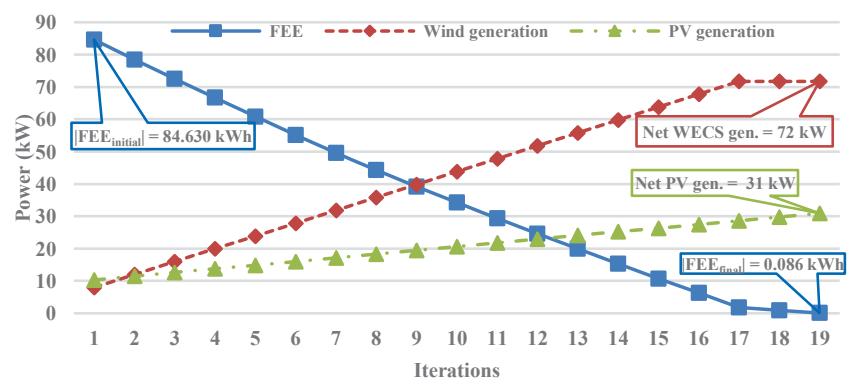

Fig. 8 Variation in magnitude of FEE and energy generated by WECS and PV on RESCA implementation with FEE constraint

Table III Cascade table obtained for RESCA implementation with only FEE constraint for HRES with $N_{W}=18, N_{P V}=27$ and $N_{\text {bat }}=6$

\begin{tabular}{|c|c|c|c|c|c|c|c|c|c|c|}
\hline T (hr) & $\mathbf{L}_{t}$ (Wh) & $R_{t}\left(W / m^{2}\right)$ & $G^{P V}{ }_{t}(W h)$ & $\mathbf{W}_{t}\left(\mathbf{m} / \mathbf{s}^{2}\right)$ & $\begin{array}{c}\mathbf{G}_{\mathrm{t}} \\
(\mathrm{Wh})\end{array}$ & $\mathbf{N}_{\mathrm{t}}(\mathbf{W h})$ & $C_{t}(W h)$ & $D_{t}(W h)$ & $C E_{t}(W h)$ & $\operatorname{NCE}_{t}(\mathrm{Wh})$ \\
\hline 1 & 2500 & 0 & 0 & 3.86 & 2880 & 380 & 302 & 0 & 302 & $302+13274$ \\
\hline 2 & 2000 & 0 & 0 & 3.82 & 2795 & 795 & 632 & 0 & 934 & 14208 \\
\hline 3 & 1000 & 0 & 0 & 3.74 & 2626 & 1626 & 1292 & 0 & 2226 & 15500 \\
\hline 4 & 2000 & 0 & 0 & 3.63 & 2393 & 393 & 312 & 0 & 2538 & 15812 \\
\hline 5 & 2000 & 0 & 0 & 3.51 & 2139 & 139 & 110 & 0 & 2649 & 15922 \\
\hline 6 & 1000 & 0 & 0 & 3.4 & 1906 & 906 & 720 & 0 & 3369 & 16642 \\
\hline 7 & 3500 & 7 & 54 & 3.3 & 1694 & -1757 & 0 & -2211 & 1157 & 14431 \\
\hline 8 & 7500 & 108 & 831 & 3.24 & 1567 & -5185 & 0 & -6524 & -5367 & 7906 \\
\hline 9 & 10000 & 289 & 2224 & 3.31 & 1715 & -6283 & 0 & -7906 & -13274 & 0 \\
\hline
\end{tabular}




\begin{tabular}{|c|c|c|c|c|c|c|c|c|c|c|}
\hline 10 & 4000 & 457 & 3517 & 3.57 & 2266 & 1431 & 1137 & 0 & -12137 & 1137 \\
\hline 11 & 4000 & 571 & 4394 & 3.82 & 2795 & 2750 & 2185 & 0 & -9951 & 3322 \\
\hline 12 & 4000 & 602 & 4632 & 4.08 & 3346 & 3515 & 2793 & 0 & -7158 & 6116 \\
\hline 13 & 4000 & 604 & 4648 & 4.35 & 3918 & 4101 & 3259 & 0 & -3899 & 9374 \\
\hline 14 & 1800 & 567 & 4363 & 4.58 & 4405 & 6531 & 5191 & 0 & 1291 & 14565 \\
\hline 15 & 2000 & 434 & 3340 & 4.7 & 4659 & 5664 & 4502 & 0 & 5793 & 19067 \\
\hline 16 & 1800 & 273 & 2101 & 4.67 & 4595 & 4686 & 3724 & 0 & 9517 & 22791 \\
\hline 17 & 1800 & 100 & 770 & 4.46 & 4151 & 3043 & 2418 & 0 & 11935 & 25209 \\
\hline 18 & 1800 & 7 & 54 & 4.33 & 3875 & 2124 & 1688 & 0 & 13623 & 26897 \\
\hline 19 & 1800 & 0 & 0 & 4.16 & 3515 & 1715 & 1363 & 0 & 14986 & 28260 \\
\hline $\mathbf{2 0}$ & $\mathbf{2 0 0 0}$ & $\mathbf{0}$ & $\mathbf{0}$ & 4.01 & $\mathbf{3 1 9 8}$ & $\mathbf{1 1 9 8}$ & $\mathbf{9 5 2}$ & $\mathbf{0}$ & $\mathbf{1 5 9 3 8}$ & $\mathbf{2 9 2 1 2}$ \\
\hline 21 & 3000 & 0 & 0 & 3.88 & 2922 & -78 & 0 & -98 & 15840 & 29114 \\
\hline 22 & 9000 & 0 & 0 & 3.81 & 2774 & -6226 & 0 & -7834 & 8006 & 21280 \\
\hline 23 & 7000 & 0 & 0 & 3.81 & 2774 & -4226 & 0 & -5318 & 2688 & 15962 \\
\hline 24 & 5000 & 0 & 0 & 3.82 & 2795 & -2205 & 0 & -2774 & -86 & 13188 \\
\hline
\end{tabular}

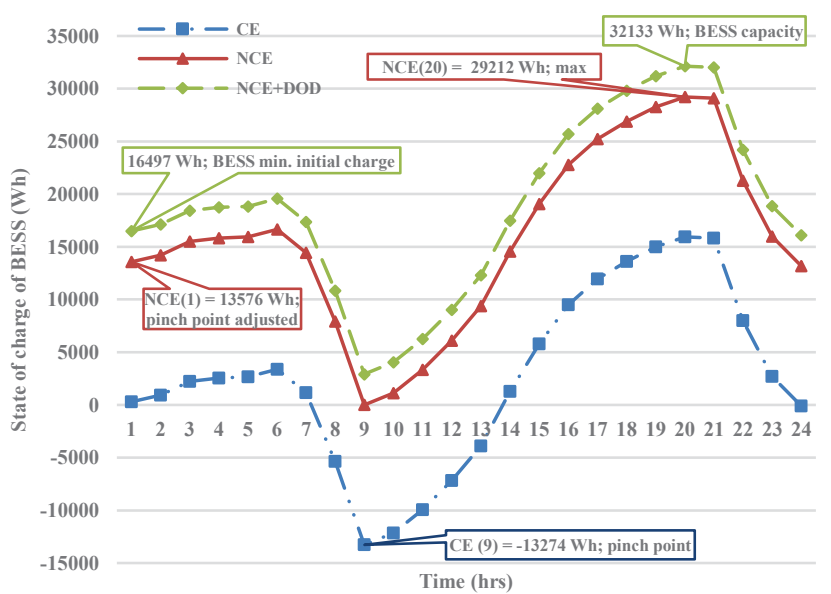

Fig. 9 State of charge of BESS with and without pinch point adjustment on RESCA implementation with FEE constraint

\section{B. Implementation of RESCA with COE and FEE constraints}

The application of RESCA with COE and FEE constraints requires implementation of methodology as shown in Fig. 5. The optimized size of PV with FEE constraint of $+100 \mathrm{Wh}$ is obtained as the size of $N_{W}$ (larger rating energy source) is fixed and increased after PV optimization. $N_{W}$ is incremented until the optimized size of PV (smaller rated energy source) obtained is less than 1 . The different configurations of $N_{W}$, $N_{P V}, N_{\text {bat }}, G_{t}^{P V}$ and $G_{t}^{W}$ are tabulated and $C O E$ is found for each configuration using (15-17). The net power generated by WECS and PV and $N_{b a t}$ obtained for each configuration is shown in Fig. 10. As $N_{W}$ is increased the power generated by PV decreases and also there is a sizeable decrease in $N_{b a t}$. The $C O E$ calculated for each configuration and the energy cost of the PV system and WECS (excluding BESS cost) is presented in Fig. 11. The lowest value of $C O E$ obtained is $0.4041 \$ / \mathrm{kWh}$ for $N_{W}=20, N_{P V}=19$ and $N_{b a t}=6$.

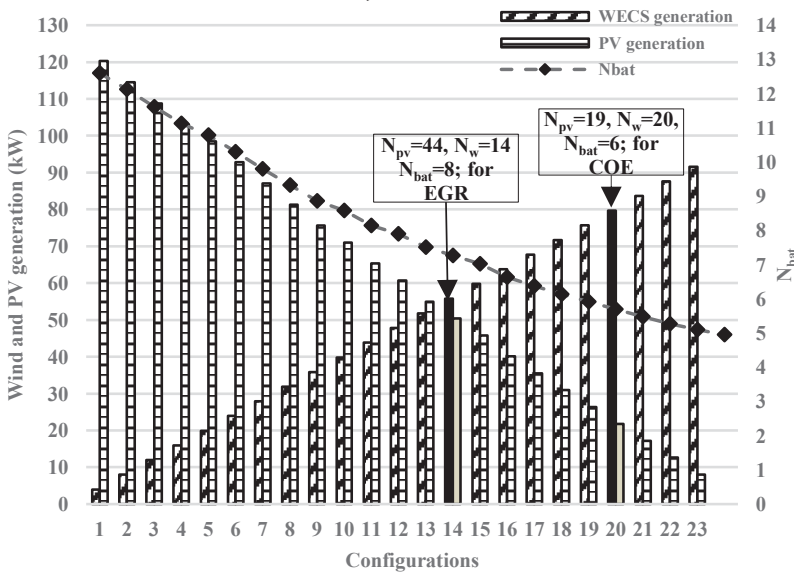

Fig. 10 Variation of energy produced by wind and PV on RESCA implementation with COE constraint
The $C O E$ of $\mathrm{PV}$ is high in comparison to WECS as seen from Fig. 11, therefore in the optimized result obtained the energy generation burden is higher for WECS. For the HRES COE the BESS cost is also included.

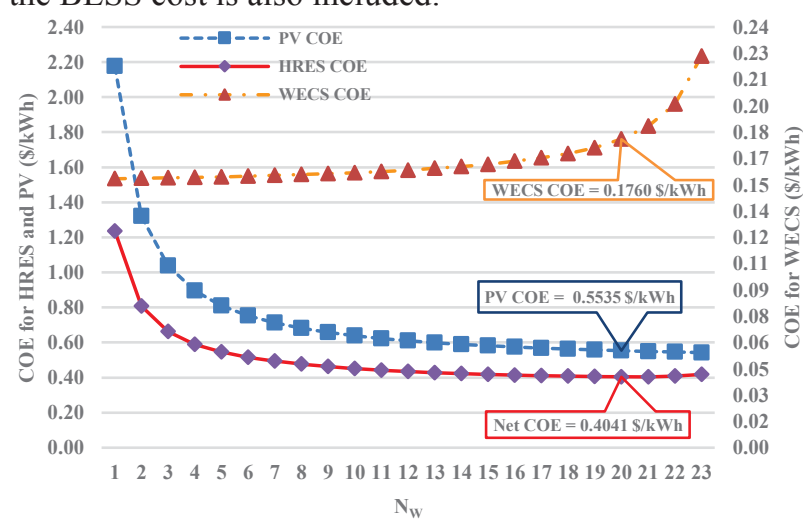

Fig. 11 Variation of COE and cost of energy of WECS and PV on RESCA implementation with $\mathrm{COE}$ constraint

\section{Implementation of RESCA with EGR and FEE optimization constraints}

RESCA methodology as shown in Fig. 4 is implemented for $E G R$ and FEE constraints. Tolerance of $+100 \mathrm{Wh}$ is set for $F E E$ and $10 \%$ for $E G R$, an initial estimate of $N_{P V}=5, N_{W}=5$ and zero initial charge in BESS is assumed. A total of 45 iterations are performed before the constraints are satisfied. The variations in $G F_{W}, G F_{P V}, E G R$ and magnitude of $F E E$ with each iteration are shown in Fig. 12.

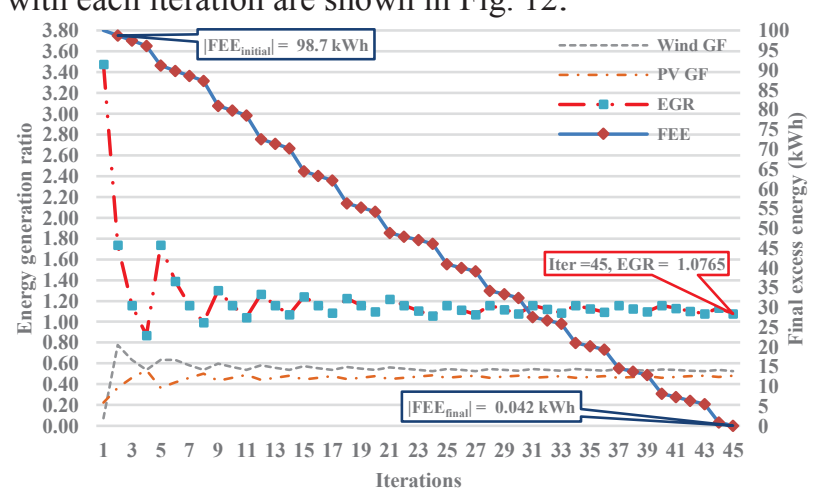

Fig. 12 Variation of EGR, magnitude of FEE and energy fraction of wind and PV on RESCA implementation with EGR constraint

Initially FEE of $-98.7 \mathrm{kWh}$ and $E G R$ of 3.56 is obtained, but as the iteration progresses the FEE decreases and $E G R$ is optimized. After 45 iterations optimum values of $\mathrm{N}_{\mathrm{PV}}=44$, $N_{W}=14$ and $N_{b a t}=8$, are obtained for which the $F E E=+42$ Wh and $E G R=1.0765$. 


\section{Implementation of RESCA with REF and FEE optimization constraints}

Due to the constant supply of energy provided by the NIS (bio-mass generator in this case) the inconsistencies of the energy supply from PV and wind is reduced considerably. For HRES with NIS, the load is reduced by the rating of NIS and the optimized system size is found using FEE and EGR constraints. On the application of RESCA for the load considered the system configuration with increase in $R E F$ is shown in Fig. 13. As seen from the Fig. 13, as the REF increases the size of NIS decreases and the energy generation shifts to PV and WECS. Also increase in the storage unit size is observed as $R E F$ increases, due to irregularity in energy supplied by PV and WECS.

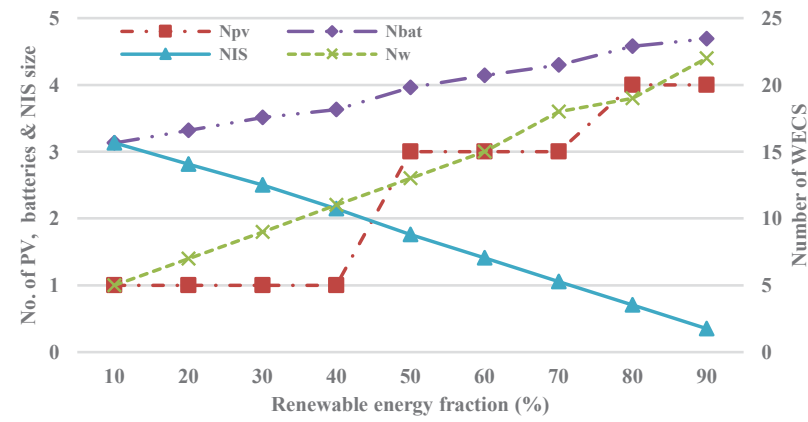

Fig. 13 Variation of number of wind turbines and PV on implementation of RESCA with REF and FEE constraints

\section{E. Comparison with HOMER and other optimization techniques}

For validating the results obtained from the RESCA methodology the optimization is also performed with HOMER considering an isolated HRES with the PV, WECS and BESS as system components. Since the data considered for analysis is of 24 hours the scaling factor of load and energy sources is set to unity. The sensitivity variable considered for system components are: numbers of WECS 10 to 25 , PV system 20 to 50 , batteries 4 to 9 and the maximum allowed capacity shortage parameter is set to zero (since RESCA is realized for no loss of power). The optimized results obtained from $\mathrm{HOMER}$ is $\mathrm{N}_{\mathrm{PV}}=40, \mathrm{~N}_{\mathrm{W}}=15$ and $\mathrm{N}_{\text {bat }}$ $=7$.

HOMER optimizes the system based on only NPC constraint. Therefore, the RESCA is also implemented with NPC and FEE constraint. The methodology adopted for NPC and FEE optimization is similar to that of COE as shown in Fig. 5. But instead of finding the COE of each optimized configuration NPC is found. The formulation of NPC can be found in [43]. A comparative study of the optimized system configurations obtained from RESCA and HOMER is presented in Table IV. The inferences drawn are as follows:

i. The optimized results obtained from RESCA and HOMER for NPC optimized constraint are comparable, which validates the proposed RESCA methodology.

ii. The optimized result obtained from HOMER and RESCA for NPC constraint has higher contribution of PV in comparison to wind.

iii. Since PV system has lower system cost in comparison to WECS, therefore for optimization with NPC constraint has higher contribution of PV in comparison to wind.

iv. The economic analysis in RESCA can also be done based on $\mathrm{COE}$, which shows higher contribution of WECS, because WECS has lower cost per unit of energy generated in comparison to PV as seen from Fig. 11.

v. The optimized results obtained from RESCA, for all optimization constraints except EGR has higher contribution of wind in comparison to PV.

vi. The BESS capacity increases with increase in the PV system rating because of sizeable irregularities in PV generation.

vii. The converter size rating is fixed by the maximum load. viii.Reduction in rating of PV, WECS, BESS capacity and NPC is observed with inclusion of NIS.

It is to be noted that economic optimization in case of RESCA can be performed with any of the cost parameters like NPC, TSC, annualized system cost, etc. with change in formulation of the cost parameter (for e.g. COE is chosen for the scope of this paper). But this flexibility is not available in HOMER, which can only optimize based on NPC. To further emphasise the novelty and credibility of RESCA over other optimization techniques, a comparison is presented in Table $\mathrm{V}$.

Table IV Comparison of optimized results obtained for various constraints

\begin{tabular}{|c|c|c|c|c|c|c|c|}
\hline \multirow[b]{2}{*}{ Parameter } & \multicolumn{6}{|c|}{ RESCA } & \multirow{2}{*}{$\begin{array}{c}\text { HOMER } \\
\text { NPC }\end{array}$} \\
\hline & FEE & $\begin{array}{l}\text { FEE, } \\
\text { COE }\end{array}$ & $\begin{array}{l}\text { FEE, } \\
\text { EGR }\end{array}$ & $\begin{array}{l}\text { REF, } \\
\text { FEE }\end{array}$ & $\begin{array}{l}\text { REF, } \\
\text { EGR }\end{array}$ & $\begin{array}{l}\text { FEE, } \\
\text { NPC }\end{array}$ & \\
\hline $\mathrm{N}_{\mathrm{w}}$ & 18 & 20 & 14 & 15 & 13 & 15 & 15 \\
\hline$N_{P V}$ & 27 & 19 & 44 & 26 & 42 & 38 & 40 \\
\hline $\mathbf{N}_{\text {Bat }}$ & 6 & 6 & 8 & 6 & 7 & 7 & 7 \\
\hline $\begin{array}{c}\mathbf{G}_{\mathrm{W}} \\
\text { (kW/day) }\end{array}$ & 72 & 80 & 56 & 60 & 52 & 60 & 60 \\
\hline $\begin{array}{c}\text { Gpv } \\
\text { (kW/day) }\end{array}$ & 31 & 22 & 53 & 30 & 48 & 42 & 45 \\
\hline NIS (kW) & 0 & 0 & 0 & 5.28 & 5.28 & 0 & 0 \\
\hline REF (\%) & 100 & 100 & 100 & 85 & 85 & 100 & 100 \\
\hline NPC (\$) & 111,493 & 115,009 & 118,493 & 105,983 & 104,311 & 110,520 & 110,930 \\
\hline $\begin{array}{l}\text { COE } \\
\text { (\$/kWh) }\end{array}$ & 0.4064 & 0.4041 & 0.4280 & 0.4222 & 0.4290 & 0.4179 & 0.4182 \\
\hline EGR & 2.3184 & 3.6613 & 1.0765 & 2.0064 & 1.0736 & 1.5384 & 1.3333 \\
\hline FEE (Wh) & +86 & +29 & +42 & +32 & +62 & +98 & +286 \\
\hline
\end{tabular}

Table V Comparison of various optimization techniques with RESCA [17], [18], [35], [43]

\begin{tabular}{|c|c|c|}
\hline $\begin{array}{c}\text { Optimisation } \\
\text { techniques }\end{array}$ & Demerits & RESCA improvements \\
\hline \multirow{7}{*}{$\begin{array}{l}\text { Software } \\
\text { based }\end{array}$} & $\begin{array}{l}\text { Only considers a single } \\
\text { objective function to minimize } \\
\text { cost (e.g. NPC for HOMER). }\end{array}$ & $\begin{array}{l}\text { Both reliability and cost } \\
\text { can be analysed based on } \\
\text { various constraints. }\end{array}$ \\
\hline & $\begin{array}{l}\text { Minimum time step of analysis } \\
\text { cannot be less than one hour. }\end{array}$ & $\begin{array}{l}\text { The time step of analysis } \\
\text { can be less than one hour } \\
\text { provided data is available. }\end{array}$ \\
\hline & $\begin{array}{l}\text { The code used for optimization } \\
\text { is a "black box" and the user } \\
\text { gets no information on why or } \\
\text { how the results are obtained. }\end{array}$ & $\begin{array}{l}\text { The user can understand } \\
\text { how a particular result is } \\
\text { obtained. }\end{array}$ \\
\hline & $\begin{array}{l}\text { In RETScreen, extraction of } \\
\text { time series data is not possible. }\end{array}$ & It can be extracted. \\
\hline & $\begin{array}{l}\text { In iHOGA, system with } \\
\text { maximum daily average load } \\
\text { more than } 10 \mathrm{kWh} \text { cannot be } \\
\text { simulated. }\end{array}$ & $\begin{array}{l}\text { No restriction is imposed } \\
\text { here. }\end{array}$ \\
\hline & $\begin{array}{l}\text { In HYBRID2, not all } \\
\text { performance parameters can be } \\
\text { accessed. }\end{array}$ & $\begin{array}{l}\text { All the system and } \\
\text { optimization parameters } \\
\text { can be accessed and } \\
\text { represented in graphs and } \\
\text { tables. }\end{array}$ \\
\hline & $\begin{array}{l}\text { The optimized results obtained } \\
\text { are limited to the input range of } \\
\text { the user, while the most } \\
\text { optimum solution may lie } \\
\text { beyond the predefined range. }\end{array}$ & $\begin{array}{l}\text { Irrespective of the initial } \\
\text { assumption, global } \\
\text { optimum solution is } \\
\text { obtained. However, rate } \\
\text { of convergence may be } \\
\text { affected. }\end{array}$ \\
\hline \multirow{4}{*}{$\begin{array}{l}\text { Artificial } \\
\text { Intelligence } \\
\text { (AI) }\end{array}$} & $\begin{array}{l}\text { For GA techniques there is } \\
\text { guarantee to find the best } \\
\text { solution. }\end{array}$ & $\begin{array}{l}\text { Always global optimum } \\
\text { solution is found. }\end{array}$ \\
\hline & $\begin{array}{l}\text { High probability of algorithm } \\
\text { converging at a local minima if } \\
\text { population generated is not } \\
\text { sufficient. }\end{array}$ & $\begin{array}{l}\text { Global optimum solution } \\
\text { found is independent of } \\
\text { initial assumption. }\end{array}$ \\
\hline & $\begin{array}{l}\text { For PSO, several modifications } \\
\text { are required for AI techniques } \\
\text { to be implemented for HRES. }\end{array}$ & $\begin{array}{l}\text { Inherently built for hybrid } \\
\text { energy systems. }\end{array}$ \\
\hline & $\begin{array}{lcr}\text { For SA, } & \text { several } & \text { initial } \\
\text { assumptions } & \text { are } & \text { required }\end{array}$ & $\begin{array}{l}\text { Only initial assumption of } \\
\mathrm{N}_{P V}, \mathrm{~N}_{W} \text { and BESS initial }\end{array}$ \\
\hline
\end{tabular}




\begin{tabular}{|l|l|l|}
\hline & $\begin{array}{l}\text { which strongly affect the final } \\
\text { result. }\end{array}$ & $\begin{array}{l}\text { charge is required which } \\
\text { has no effect on the final } \\
\text { result. Though the rate of } \\
\text { convergence can be } \\
\text { affected. }\end{array}$ \\
\hline & $\begin{array}{l}\text { For HS, complex optimization } \\
\text { problem may lead to premature } \\
\text { convergence. }\end{array}$ & $\begin{array}{l}\text { Can handle HRES with } \\
\text { different configurations } \\
\text { and system components. }\end{array}$ \\
\hline $\begin{array}{l}\text { For fuzzy logic approach it is } \\
\text { difficult to formulate the } \\
\text { membership function. }\end{array}$ & $\begin{array}{l}\text { No such difficulty here. } \\
\text { Analogues models have to be } \\
\text { created thus making system } \\
\text { modelling complex. }\end{array}$ & $\begin{array}{l}\text { Inherently built for } \\
\text { renewable energy system, }\end{array}$ \\
\hline $\begin{array}{l}\text { For neural network technique, } \\
\text { higher processing time for } \\
\text { training and modelling the } \\
\text { system is required. }\end{array}$ & $\begin{array}{l}\text { Processing time and } \\
\text { power is relatively less } \\
\text { and independent of the } \\
\text { system component } \\
\text { modelling. com }\end{array}$ \\
\hline
\end{tabular}

\section{CONCLUSION}

This paper has presented the implementation of the RESCA technique for optimization of HRES consisting of PV, WECS and BESS. The versatility of this method lies in its ability of handling multi-criteria and multi-source optimization. The application of RESCA is shown for constraints like FEE, $C O E, N P C, E G R$ and $R E F$ for which the optimized configuration of the system components obtained vary depending on the chosen constraints. RESCA has shown its resourcefulness as it manages to provide the user with better insight of the influence of variation in wind speed and solar radiation on the PV and WECS power generation, charging/discharging trends of the BESS and identifying the optimal size of the BESS and energy sources through the cascade table. The results obtained are also compared with HOMER, which shows the flexibility of RESCA over HOMER in case of economic optimization constraints. The credibility of RESCA is bolstered by its capability to overcome drawbacks of other optimization techniques. The application of RESCA is limited for 24 hours time period which will be addressed in the future work for better realworld application of the technique, also the work is in progress for application of RESCA for grid connected HRES optimization.

\section{REFERENCES}

[1] J. Twidell and T. Weir, Renewable Energy Resources. New York, USA: Routledge, 2015.

[2] Energy Information Administration (US), International Energy Outlook 2013 with Projections to 2040. Government Printing Office, 2013.

[3] A. Chauhan and R. P. Saini, "A review on integrated renewable energy system based power generation for standalone applications: configurations, storage options, sizing methodologies and control," Renewable and Sustainable Energy Reviews, vol. 38, pp. 99-120, Oct. 2014.

[4] N. U. Blum, R. S.Wakeling, and T. S. Schmidt, "Rural electrification through village grids-Assessing the cost competitiveness of isolated renewable energy technologies in Indonesia," Renewable and Sustainable Energy Reviews, vol. 22, pp. 482-496, Jun. 2013.

[5] C. Lupangu and R. C. Bansal, "A review of technical issues on the development of solar photovoltaic systems," Renewable and Sustainable Energy Reviews, vol. 73, pp. 950-965, Jun. 2017.

[6] R. Dubey, D. Joshi, and R. C. Bansal, "Optimization of solar photovoltaic plant and economic analysis," Electric Power Components and Systems, vol. 44, no. 18, pp. 2025-2035, Nov. 2016

[7] B. Zakeri and S. Syri, "Electrical energy storage systems: A comparative life cycle cost analysis," Renewable and
Sustainable Energy Reviews, vol. 42, pp. 569-596, Feb. 2015.

[8] K. Jia, Y. Chen, T. Bi, Y. Lin, D. Thomas, and M. Sumner, "Historical data based energy management in a micro-grid with a hybrid energy storage system," IEEE Transactions on Industrial Informatics, vol. PP, no. 99, pp. 1-1, 2017.

[9] S. Upadhyay and M. P. Sharma, "Development of hybrid energy system with cycle charging strategy using particle swarm optimization for a remote area in India," Renewable Energy, vol. 77, pp. 586-598, May 2015.

[10] A. Maleki and A. Askarzadeh, "Comparative study of artificial intelligence techniques for sizing of a hydrogenbased stand-alone photovoltaic/wind hybrid system," International Journal of Hydrogen Energy, vol. 39, no. 19, pp. 9973-9984, Jun. 2014.

[11] Y. A. Katsigiannis, P. S. Georgilakis, and E. S. Karapidakis, "Hybrid simulated annealing -tabu search method for optimal sizing of autonomous power systems with renewables," IEEE Transactions on Sustainable Energy, vol. 3, no. 3, pp. 330-338, Jul. 2012.

[12] P. Paliwal, N. P. Patidar, and R. K. Nema, "Determination of reliability constrained optimal resource mix for an autonomous hybrid power system using Particle Swarm Optimization," Renewable Energy, vol. 63, pp. 194-204, Mar. 2014

[13] E. Koutroulis and D. Kolokotsa, "Design optimization of desalination systems power-supplied by PV and W/G energy sources," Desalination, vol. 258, no. 1-3, pp. 171-181, Aug. 2010.

[14] S. Bahramara, M. P. Moghaddam, and M. R. Haghifam, "Optimal planning of hybrid renewable energy systems using HOMER: A review," Renewable and Sustainable Energy Reviews, vol. 62, pp. 609-620, Sep. 2016.

[15] T. Hove and H. Tazvinga, "A techno-economic model for optimising component sizing and energy dispatch strategy for PV-diesel-battery hybrid power systems," Journal of Energy in Southern Africa, vol. 23, no. 4, pp. 18-28, 2012.

[16] R. Singh, S. Awasthi, and G. Khanduri, "A case study on economic viability of a stand-alone and grid connected generation system for Mumbai," in International Conference on Industrial Electronics and Electrical Engineering, Banglore, 2016, vol. 4, pp. 14-19.

[17] S. Sinha and S. S. Chandel, "Review of software tools for hybrid renewable energy systems," Renewable and Sustainable Energy Reviews, vol. 32, pp. 192-205, Apr. 2014.

[18] A. Ansari and A. A. Bakar, "A Comparative Study of Three Artificial Intelligence Techniques: Genetic Algorithm, Neural Network, and Fuzzy Logic, on Scheduling Problem," 2014, pp. 31-36.

[19] W. H. Liu, K. Kaliappan, S. R. W. Alwi, J. S. Lim, and W. S. Ho, "Power Pinch Analysis supply side management: strategy on purchasing and selling of electricity," Clean Techn Environ Policy, vol. 18, no. 8, pp. 2401-2418, Dec. 2016.

[20] S. R. Wan Alwi, N. E. Mohammad Rozali, Z. Abdul-Manan, and J. J. Klemeš, "A process integration targeting method for hybrid power systems," Energy, vol. 44, no. 1, pp. 6-10, Aug. 2012.

[21] S. Bandyopadhyay, "Design and optimization of isolated energy systems through pinch analysis," Asia-Pacific Jrnl of Chem. Eng, vol. 6, no. 3, pp. 518-526, May 2011.

[22] W. S. Ho, H. Hashim, M. H. Hassim, Z. A. Muis, and N. L. M. Shamsuddin, "Design of distributed energy system through Electric System Cascade Analysis (ESCA)," Applied Energy, vol. 99, pp. 309-315, Nov. 2012.

[23] W. S. Ho, M. Z. W. M. Tohid, H. Hashim, and Z. A. Muis, "Electric System Cascade Analysis (ESCA): solar PV system," International Journal of Electrical Power \& Energy Systems, vol. 54, pp. 481-486, Jan. 2014. 
[24] P. Nema, R. K. Nema, and S. Rangnekar, "A current and future state of art development of hybrid energy system using wind and PV-solar: A review," Renewable and Sustainable Energy Reviews, vol. 13, no. 8, pp. 2096-2103, Oct. 2009.

[25] I. Patrao, E. Figueres, G. Garcerá, and R. González-Medina, "Microgrid architectures for low voltage distributed generation," Renewable and Sustainable Energy Reviews, vol. 43, pp. 415-424, Mar. 2015.

[26] R. C. Bansal and T. S. Bhatti, Small signal analysis of isolated hybrid power systems: reactive power and frequency control analysis, Oxford United Kingdom: Alpha Science, 2008.

[27] D. Wu, F. Tang, T. Dragicevic, J. C. Vasquez, and J. M. Guerrero, "A control architecture to coordinate renewable energy sources and energy storage systems in islanded microgrids," IEEE Transactions on Smart Grid, vol. 6, no. 3, pp. 1156-1166, May 2015.

[28] H. R. Baghaee, M. Mirsalim, G. B. Gharehpetian, and H. A. Talebi, "A decentralized power management and sliding mode control strategy for hybrid AC/DC microgrids including renewable energy resources," IEEE Transactions on Industrial Informatics, vol. PP, no. 99, pp. 1-1, 2017.

[29] R. Hosseinalizadeh, H. Shakouri G, M. S. Amalnick, and P. Taghipour, "Economic sizing of a hybrid (PV-WT-FC) renewable energy system (HRES) for stand-alone usages by an optimization-simulation model: Case study of Iran," Renewable and Sustainable Energy Reviews, vol. 54, pp. 139-150, Feb. 2016.

[30] R. C. Bansal, Handbook of Distributed Generation: Electric Power Technologies, Economics and Environmental Impacts. Switzerland: Springer, 2017.

[31] M. B. Ozkan and P. Karagoz, "A novel wind power forecast model: statistical hybrid wind power forecast technique (SHWIP)," IEEE Transactions on Industrial Informatics, vol. 11, no. 2, pp. 375-387, Apr. 2015.

[32] M. K. Deshmukh and S. S. Deshmukh, "Modeling of hybrid renewable energy systems," Renewable and Sustainable Energy Reviews, vol. 12, no. 1, pp. 235-249, Jan. 2008.

[33] H. Wei, H. Zijun, F. Li, T. Hongliang, and Z. Li, "Reliability evaluation of Microgrid with PV-WG hybrid system," in IEEE, 4th International Conference on Electric Utility Deregulation and Restructuring and Power Technologies (DRPT), China, 2011, pp. 1629-1632.

[34] K. Chaudhari, A. Ukil, K. N. Kumar, U. Manandhar, and S. K. Kollimalla, "Hybrid optimization for economic deployment of ESS in PV integrated EV charging station," IEEE Transactions on Industrial Informatics, vol. PP, no. 99, pp. 1-1, 2017.

[35] R. Singh and R. C. Bansal, "Review of HRESs based on storage options, system architecture and optimisation criteria and methodologies," IET Renewable Power Generation, vol. 12, no. 7, pp. 747-760, May 2018.

[36] "IEEE Guide for Electric Power Distribution Reliability Indices," IEEE Std 1366-2003 (Revision of IEEE Std 13661998), pp. 1-50, May 2004.

[37] K. Kant, C. Jain, and B. Singh, "A hybrid diesel-wind pvbased energy generation system with brushless generators," IEEE Transactions on Industrial Informatics, vol. 13, no. 4, pp. 1714-1722, Aug. 2017.

[38] A. H. Fathima and K. Palanisamy, "Optimization in microgrids with hybrid energy systems - A review," Renewable and Sustainable Energy Reviews, vol. 45, pp. 431-446, May 2015.

[39] R. Singh, R. C. Bansal, and N. Tiwari, "Optimization and comparison of autonomous renewable energy system based on ESCA technique," presented at the IEEE International WIE Conference on Electrical and Computer Engineering, Dehradun, India, 2017, pp. 1-5.

[40] "U.S. Wind Climatology, National Centers for Environmental Information (NCEI).” [Online]. Available: https://www.ncdc.noaa.gov/societal-impacts/wind/wmean/201601. [Accessed: 19-Jul-2017].

[41] K. H. Chua, Y. S. Lim, and S. Morris, "Cost-benefit assessment of energy storage for utility and customers: A case study in Malaysia," Energy Conversion and Management, vol. 106, pp. 1071-1081, Dec. 2015.

[42] " $1 \mathrm{~kW}$ wind turbine - fixed pitch wind turbine - wind turbine manufacture-Shandong Huaya industry Co." [Online]. Available:

http://www.huayaturbine.com/te_product_a/2010-1225/228.chtml. [Accessed: 28-Aug-2017].

[43] R. Siddaiah and R. P. Saini, "A review on planning, configurations, modeling and optimization techniques of hybrid renewable energy systems for off grid applications," Renewable and Sustainable Energy Reviews, vol. 58, pp. 376-396, May 2016.

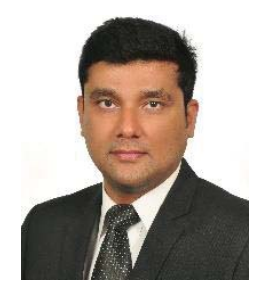

Ranjay Singh completed his B.E. in Electrical Engineering from Panjab University, Chandigarh, India in 2011 and M.Tech in Power Electronics from Motilal Nehru National Institute of Technology, Allahabad, India in 2014. He has worked as Assistant Professor in the department of Electrical Engineering at DIT University, Dehradun, India from 2014 to 2016 . He is currently pursuing his $\mathrm{PhD}$ in the field of Optimization of Hybrid Renewable Energy Systems from department of Electrical Engineering at University of Pretoria, Pretoria, South Africa. His research interests include renewable energy system optimization, power system, smart grid and microgrids.

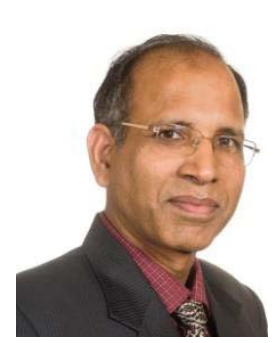

RAMESH C. BANSAL (SM'03) has more than 25 years' experience in teaching, research, and industry. He was with the University of Queensland, Australia, the University of the South Pacific, Fiji, the Birla Institute of Technology and Science, Pilani, India, and the Civil Construction Wing of AllIndia Radio. He has with Powerlink, an Australian government-owned corporation responsible for Queensland's high-voltage electricity transmission network. He has significant industrial experience involved with power utilities, includes NTPC (A 40 GW Indian Power Generation Company) and ESKOM (Generation, Transmission \& Distribution Company in Africa). He is currently a Professor and a Group Head (Power) with the Department of Electrical, Electronic and Computer Engineering, University of Pretoria. He has published over 275 journal articles, presented papers at conferences, and has contributed to books and chapters in books. He has supervised 18 Ph.D. students and currently supervising $10 \mathrm{Ph} . \mathrm{D}$. students. His diversified research interests include in the areas of renewable energy and conventional power systems, include wind, photovoltaics, hybrid power systems, distributed generation, grid integration of renewable energy, power systems analysis, smart grid, flexible ac transmission systems, and power quality. He is a Fellow and a Chartered Engineer of the Institution of Engineering and Technology, U.K., a fellow of the Engineers Australia, and a fellow of the Institution of Engineers, India. He is an Editor of the highly regarded journals, IET Renewable Power Generation (regional editor for Africa) and Electric Power Components and Systems. 